\title{
A Response to "Predictors of Intention to Get a COVID-19 Vaccine of Health Science Students: A Cross-Sectional Study.” [Letter]
}

\section{Aanchal Gupta \\ Roshan Jonash Raymond}

Barts and The London School of Medicine and Dentistry, London, UK
Correspondence: Aanchal Gupta Barts and The London School of Medicine and Dentistry, Garrod Building, Turner Street, Whitechapel, London, EI 2AD, UK

Tel +447946769695

Email a.gupta@smdI6.qmul.ac.uk

\section{Dear editor}

We read, with great interest, the paper by Nguyen et al, exploring the intention of health science students to get a COVID-19 vaccine. ${ }^{1}$ There are many considerations to getting the vaccine and we thank the authors for providing a student focussed insight. As final year medical students, we have experienced the last two years of our training in the pandemic and therefore recognise the importance of the vaccine. Moreover, through our role as vaccinators, we understand the greatly varying attitudes of the population; thus, we would like to offer our perspectives on the Study.

It was insightful to read the perspectives of Vietnamese health students and understand some of the reasons for their vaccine hesitancy. However, we do not know whether the students had pre-existing health conditions which may have increased their risk of morbidity and mortality from COVID-19. This is crucial as it increases both the likelihood of them being offered the vaccine and the uptake. Perhaps, the authors could have asked the students to calculate a COVID risk score, thereby maintaining anonymity of their health information. Additionally, the authors define one of the reasons for vaccine hesitancy as "safety". As our knowledge about each of the vaccines increased, there were more side effects discovered, one of the more notable in the media being the AstraZeneca vaccine and thromboembolism risk. It may have been pertinent to ask the students to specify what they meant by "safety" and whether it was specific to a particular vaccine. Furthermore, a study by Nguyen et al has shown that there is a greater vaccine hesitancy among racial minorities. ${ }^{3}$ This is an important factor to take into account as there will be demographic implications when studying such a population.

In our own experience, our University sent us email correspondence when we became eligible to get the vaccine. Getting reassurance from a trusted body such as a health-care provider has been shown to decrease vaccine hesitancy. ${ }^{2}$ We would have liked to know whether the students were approached in a similar manner and whether this influenced their likelihood of getting the vaccine. As vaccinators, we observed that patients were often driven by incentive (ie, being able to travel) or due to mandates from employers and schools, if not by their health conditions. There is literature to suggest that these incentives are effective, particularly when monetary. ${ }^{4}$ It may have been pertinent to assess whether these were at play in the students' case. 
The authors have asked the students which sources of information they use. Ministry of Health and Hospital websites are more likely to provide accurate and up-to-date information, whereas social media can be the source of misinformation. ${ }^{5}$ Asking participants where they get the majority of their information and assessing whether there is a correlation between this and the vaccine intention may be more useful.

In conclusion, the authors provide a multitude of predictors for vaccine hesitancy but vaccine-specific perspectives which look at the students more holistically are required.

\section{Disclosure}

The authors report no conflicts of interest in this communication.

\section{References}

1. Nguyen VT, Nguyen MQ, Le NT, Nguyen TNH, Huynh G. Predictors of intention to get a COVID-19 vaccine of health science students: a cross-sectional study. Risk Manag Healthc Policy. 2021;14:4023-4030. PMID: 34594141; PMCID: PMC8478496. doi:10.2147/RMHP.S328665

2. Reiter PL, Pennell ML, Katz ML. Acceptability of a COVID-19 vaccine among adults in the United States: how many people would get vaccinated? Vaccine. 2020;38(42):6500-6507. PMID: 32863069; PMCID: PMC7440153. doi:10.1016/j.vaccine.2020.08.043

3. Nguyen LH, Joshi AD, Drew DA, et al. Racial and ethnic differences in COVID-19 vaccine hesitancy and uptake. medRxiv. 2021. PMID: 33655271; PMCID: PMC7924296. doi:10.1101/2021.02.25.21252402

4. Savulescu J, Pugh J, Wilkinson D. Balancing incentives and disincentives for vaccination in a pandemic. Nat Med. 2021;27(9):1500-1503. PMID: 34489607. doi:10.1038/s41591-021-01466-8

5. Gabarron E, Oyeyemi SO, Wynn R. COVID-19-related misinformation on social media: a systematic review. Bull World Health Organ. 2021;99(6):455-463A. PMID: 34108756; PMCID: PMC8164188. doi:10.2471/BLT.20.276782

Dove Medical Press encourages responsible, free and frank academic debate. The content of the Risk Management and Healthcare Policy 'letters to the editor' section does not necessarily represent the views of Dove Medical Press, its officers, agents, employees, related entities or the Risk Management and Healthcare Policy editors. While all reasonable steps have been taken to confirm the content of each letter, Dove Medical Press accepts no liability in respect of the content of any letter, nor is it responsible for the content and accuracy of any letter to the editor.

\section{Publish your work in this journal}

Risk Management and Healthcare Policy is an international, peerreviewed, open access journal focusing on all aspects of public health, policy, and preventative measures to promote good health and improve morbidity and mortality in the population. The journal welcomes submitted papers covering original research, basic science, clinical \& epidemiological studies, reviews and evaluations, guidelines, expert opinion and commentary, case reports and extended reports. The manuscript management system is completely online and includes a very quick and fair peer-review system, which is all easy to use. Visit http://www.dovepress.com/testimonials.php to read real quotes from published authors. 